\title{
Tree-ring-inferred glacier mass balance variation in southeastern Tibetan Plateau and its linkage with climate variability
}

\author{
J. Duan ${ }^{1}$, L. Wang ${ }^{2}$, L. Li ${ }^{3}$, and Y. Sun ${ }^{4}$ \\ ${ }^{1}$ State Key Laboratory of Vegetation and Environmental Change, Institute of Botany, Chinese Academy of Sciences, \\ Beijing, China \\ ${ }^{2}$ Institute of Geographic Sciences and Natural Resources Research, Chinese Academy of Sciences, Beijing, China \\ ${ }^{3}$ Chinese Academy of Meteorological Sciences, Beijing, China \\ ${ }^{4}$ AVIC Finance Co., Ltd., Beijing, China \\ Correspondence to: J. Duan (duanjp@ibcas.ac.cn)
}

Received: 6 June 2013 - Published in Clim. Past Discuss.: 2 July 2013

Revised: 16 October 2013 - Accepted: 19 October 2013 - Published: 4 November 2013

\begin{abstract}
A large number of glaciers in the Tibetan Plateau (TP) have experienced wastage in recent decades. And the wastage is different from region to region, even from glacier to glacier. A better understanding of long-term glacier variations and their linkage with climate variability requires extending the presently observed records. Here we present the first tree-ring-based glacier mass balance (MB) reconstruction in the TP, performed at the Hailuogou Glacier in southeastern TP during 1868-2007. The reconstructed MB is characterized mainly by ablation over the past $140 \mathrm{yr}$, and typical melting periods occurred in 1910s-1920s, 1930s-1960s, 1970s-1980s, and the last $20 \mathrm{yr}$. After the 1900s, only a few short periods (i.e., 1920s-1930s, the 1960s and the late 1980s) were characterized by accumulation. These variations can be validated by the terminus retreat velocity of Hailuogou Glacier and the ice-core accumulation rate in Guliya and respond well to regional and Northern Hemisphere temperature anomaly. In addition, the reconstructed MB is significantly and negatively correlated with August-September all-India monsoon rainfall (AIR) $\left(r_{1871-2008}=-0.342, p<\right.$ $0.0001)$. These results suggest that temperature variability is the dominant factor for the long-term MB variation at the Hailuogou Glacier. Indian summer monsoon precipitation does not affect the MB variation, yet the significant negative correlation between the MB and the AIR implies the positive effect of summer heating of the TP on Indian summer monsoon precipitation.
\end{abstract}

\section{Introduction}

Increased glacier melting as a result of climate warming has occurred in many glaciers worldwide in recent decades (Jansen et al., 2007), which not only has led to sea-level rise in some regions but also has affected large-scale hydrological and atmospheric circulation (Jacob et al., 2012; Yao et al., 2007; Liu et al., 2012), and ultimately has threatened human safety (Bury et al., 2011). The Tibetan Plateau (TP) and surroundings contain the largest number of glaciers outside the polar regions (Yao et al., 2012), and these glaciers are largely experiencing wastage (Fujita and Nuimura, 2011; Yao et al., 2012; Bolch et al., 2012; Kääb et al., 2012), which mainly appears as the decrease of glacier areas, retreat of glacier termini or thinning of glaciers. Besides, wastage is different from region to region, even from glacier to glacier due to spatially heterogeneous response of glacier variation to climate change (Yao et al., 2012; Fujita and Nuimura, 2011; Scherler et al., 2011). Understanding of the long-term response of glacier variation to climate change is limited by the length of observed glacier records and sparse ice-core materials, especially for the southeastern TP, where the observed glacier record is scarce and short while ice-core materials have not yet been obtained owing to complex topography. Tree rings from glacial regions could be a good proxy for long-term glacier variation studying (Bräuning, 2006; Xu et al., 2012), especially for the high-resolution reconstruction of mass balance (MB) (Lewis and Smith, 2004; Watson and Luckman, 2004; Linderholm et al., 2007). MB is the difference of mass 
input (accumulation) and mass loss (ablation) on a glacier in one year, and can provide a way to evaluate their glaciological response to changing climates directly (Yarnal, 1984).

In this study, we attempt to reconstruct the annualresolution MB variation at the Hailuogou Glacier in southeastern TP back to the past two centuries using tree-ring mean latewood density (MLD) data of Abies fabri collected in the glacier region and to discuss its relationships with long-term climate change.

\section{Materials and methods}

\subsection{Study area}

The study area is located in the Hailuogou Glacier region on the east slope of Mount Gongga (7556 m a.s.l.) in the southeastern margin of the TP (Fig. 1a). The Hailuogou Glacier with a length of $13.1 \mathrm{~km}$ and an area of $25.7 \mathrm{~km}^{2}$ (Shi, 2005) extends from 7556 to $2910 \mathrm{~m}$ a.s.l. at the terminus (Zhang et al., 2010), and the glacier tongue stretches into the forest (Fig. 1b). The glacier is representative of monsoonal maritime glaciers in the southeastern TP, and characterized by both ablation and accumulation in summer (Li et al., 2010). Most of the annual precipitation (approximately $80 \%$ ) in the region occurs during May-September, and this season has the highest annual temperatures (Fig. 1c).

\subsection{Tree-ring data}

Tree-ring samples were collected from the site $\left(29^{\circ} 33^{\prime} \mathrm{N}\right.$, $102^{\circ} \mathrm{E} ; 3100 \mathrm{~m}$ a.s.l.) of old growth Abies fabri in the Hailuogou Glacier region in August 2008 (Fig. 1a and b). Two increment cores for each tree were extracted at the tree's breast height. The ring width of each tree-ring sample was processed, measured and cross-dated firstly following standard dendrochronological procedures (Fritts, 1976; Cook and Kairiukstis, 1990). After measurement and cross-dating of ring widths, samples were processed and measured for densitometric analysis following standard practices (Lenz et al., 1976; Schweingruber et al., 1988). Sugar and resin were extracted from the samples by soaking in $80^{\circ} \mathrm{C}$ water for $48 \mathrm{~h}$. After air drying, cutting into sections and measuring wood fiber angles, cores were cut into laths of $1.0 \mathrm{~mm}$ thickness with a twin-blade Dendrocut. X-ray film was taken, and the grayscale variations were measured by the DENDRO2003 instrument. The optical strength was transformed to tree-ring density. With the X-ray method, seven data sets were obtained (earlywood and latewood widths, mean earlywood and latewood densities, maximum and minimum densities, and total tree-ring widths) (Duan et al., 2010a). Tree-ring density dating was based on the first cross-dating of ring widths, especially when some cores were broken unavoidably during the process of sugar and resin extraction and sample sectioning. A total of 22 trees and 42 cores were successfully cross-dated, and the mean latewood density (MLD) was used

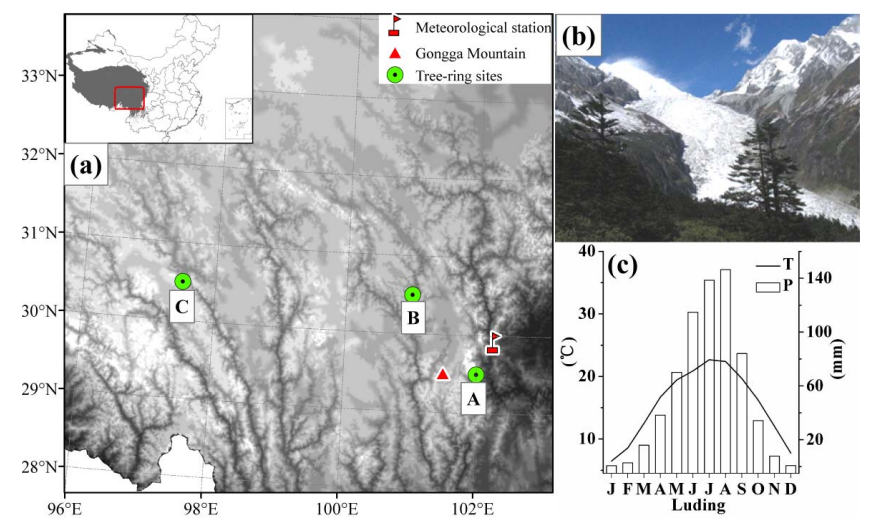

Fig. 1. (a) Location map showing the tree-ring sites and meteorological station. Letters A, B, and C are locations of the tree-ring sampling site in this study, tree-ring-based temperature reconstructions from west Sichuan Plateau (Shao and Fan, 1999) and eastern Tibet (Wang et al., 2010), respectively. (b) A picture of the study area. (c) Monthly mean temperature and monthly total precipitation in Luding meteorological station during 1957-2007.

for analysis in this study. Analyses of the tree-ring width and maximum late wood density (MXD) of the sampling site were reported in our previous studies (Duan et al., 2010a, b).

\subsection{Climatic data and glacier mass balance data}

Climate data from the nearest meteorological station (Luding station) of the study area were used (Fig. 1c). The available period of the data set was 1957-2007. The all-India monsoon rainfall (AIR) data were obtained from the Indian Institute of Tropical Meteorology (http://www.tropmet.res.in), and the data set during 1871-2007 was used. Northern Hemisphere annual temperature anomaly data (HadCRUT4) of the period 1868-2007 were extracted from the Climatic Research Unit (http://www.cru.uea.ac.uk) (Jones et al., 2012). The MB data at the Hailuogou Glacier were obtained from the record in the "Glaciers and Their Environments in China - the Present, Past and Future" (Shi, 2000). The period of the MB data set was 1960-1993.

\subsection{Methods}

Tree-ring MLD chronology was developed using the program ARSTAN, in which a cubic smoothing spline with $50 \%$ frequency-response cutoff at $67 \%$ of the series length was employed to remove non-climatic, tree-age-related growth trends. The autocorrelation was removed from each series using an autoregressive model. A biweight robust mean was applied to each series to build the residual chronology. The expressed population signal (EPS) was used to evaluate the most reliable time span of the chronology (Wigley et al., 1984). The most reliable period of the chronology established was based on the value of EPS more than 0.85 . 
Relationship between the MLD and the MB was examined using Pearson's correlation analysis over their common period. Past $\mathrm{MB}$ was reconstructed from tree rings using linear regression method. The skill of the regression model was verified using leave-one-out cross-validation method procedure (Michaelsen, 1987). The statistics for evaluation of the regression model included Pearson's correlation coefficient $(r)$, sign test (ST), first difference sign test (ST1), reduction of error (RE) and product mean test (PMT).

\section{Results}

\subsection{MLD chronology}

The MLD residual chronology established in this study covered a period of 1814-2007. The threshold of EPS $>0.85$ corresponded to a minimum sample depth of 20 cores back to 1868 (Fig. 2a).

\subsection{Reconstruction of the mass balance}

Correlation analysis displayed that the MLD residual chronology was significantly and negatively correlated with the MB over the common period 1960-1993 $(r=-0.573$, $p<0.001$ ), and the highest correlation occurred in the period 1960-1990 ( $r=-0.646, p<0.001)$. We, using the MB as the dependent variable and the MLD residual chronology as the independent variable, established the linear regression models in periods 1960-1993 and 1960-1990 respectively. The calibration and verification statistics showed that both of the two regression models passed most of the statistics ( $p<0.05$ or $p<0.001)$, except for the ST results $(p<0.1$ in the period 1960-1990; $p<0.25$ in the period 1960-1993) (Table 1). The values of $r, R^{2}$ and $F$ were all significant at the level of $p<0.001$. Positive RE indicated that the two regression models exhibited good skill in reconstructing past MB (Fritts, 1976). The PMT values, a measure of the sign and magnitude of departure from the calibration mean, were also significant at the 0.01 level. The ST1 results were also significant at the level $p<0.05$. Durbin-Watson (DW) statistics obtained from the two periods (2.42 and 2.26) denoted no first-order autocorrelation in the model residuals. These results demonstrated that both of the two regression models had good predictive skill in the reconstruction, and the second model (i.e., in period 1960-1990) was better. The second model showed that better results might be related to the anomalous climate in the period 1991-1993. Based on the climate data of the nearest meteorology station (Luding), we found that the cold-season precipitation (from previous October to current March) in the period 1991-1993 is relatively higher than the mean cold-season precipitation over the whole period 1961-1993 (the cold-season precipitation in 1991-1992 is more than the mean plus 1.1 standard deviation (SD) of the period 1961-1993). This could be conductive to the high MB. Meanwhile, the September temperature
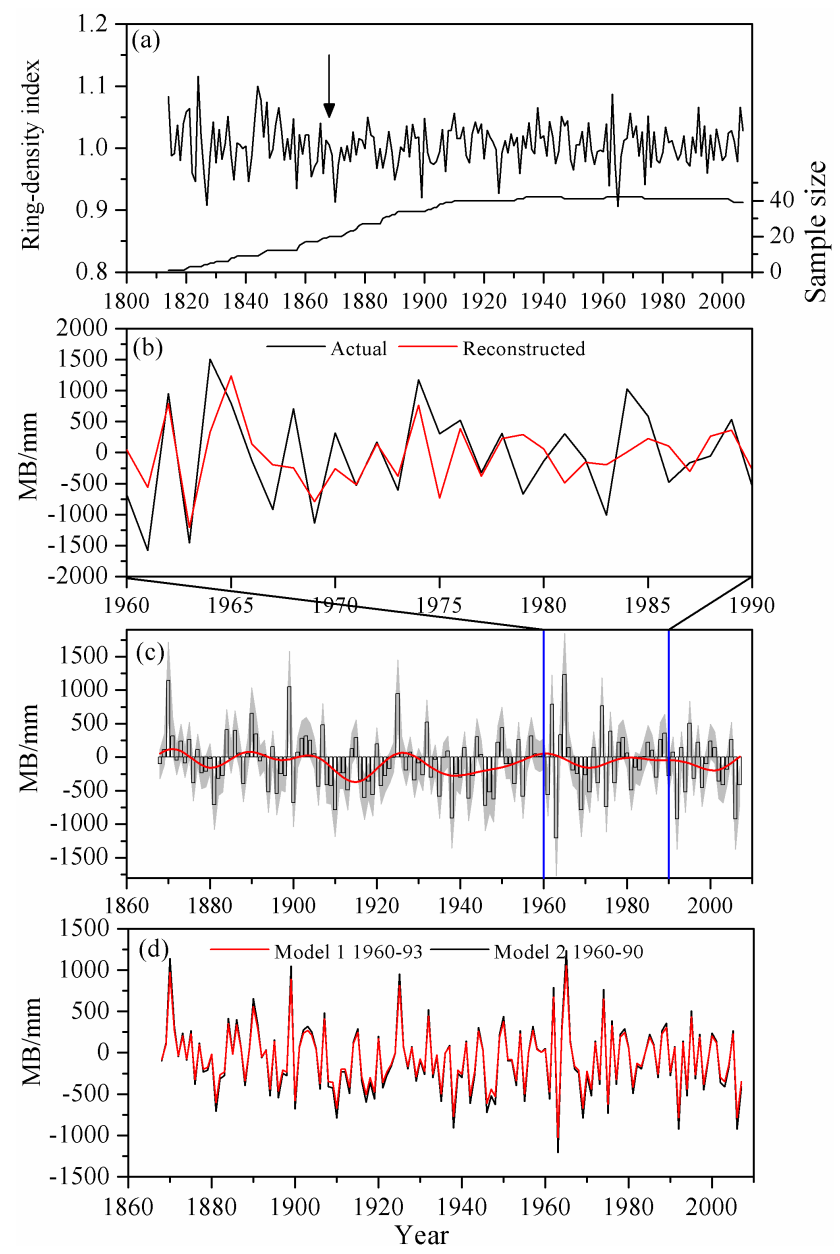

Fig. 2. (a) MLD residual chronology of Abies fabri and the sample size. Arrow denotes the year with EPS $>0.85$. (b) Comparison of actual and reconstructed MB at the Hailuogou Glacier in the period 1960-1990. (c) Reconstructed MB variability at the Hailuogou Glacier back to 1868 (black column) and its $95 \%$ confidence interval (gray shade). Red line represents the $10 \mathrm{yr}$ FFT (fast Fourier transform) smoothing curve. (d) Comparison of the reconstructions based on the two regression models (Model 1, period 1960-1993; Model 2, 1960-1990) over the period 1868-2007.

(a main month of influencing latewood density) in the period 1991-1993 is relatively higher than the mean value of the period 1960-1990 (the September temperature in 1992 is more than the mean plus 1.1 SD of the period 1960-1993), which produced the higher MLD. Consequently, both high MLD and high MB occurred in the period 1991-1993 (especially in 1992), which is contrary to the relationship of MLD with MB over the period 1960-1990 and resulted in the diluting of the result. In order to examine if using the two models could result in a divergence over the reconstruction period, we compared the reconstructions (1868-2007) based on the two models (Fig. 2d). The result shows that there is no divergence over the reconstruction period, and the second model (period 1960-1990) presents a better ability to 
Table 1. Calibration and verification statistics for the regression model.

\begin{tabular}{lccccccccc}
\hline Period & $r$ & $R^{2}$ & $R_{\text {adj }}^{2}$ & $F$ & ST & ST1 & PMT & RE & DW \\
\hline $1960-1993$ & -0.573 & $32.8 \%$ & $30.7 \%$ & 15.6 & $21+/ 13-$ & $23+/ 10-$ & 2.54 & 0.24 & 2.42 \\
$1960-1990$ & -0.646 & $41.7 \%$ & $39.7 \%$ & 20.7 & $21+/ 10-$ & $22+/ 8-$ & 2.70 & 0.34 & 2.26 \\
\hline
\end{tabular}

$r$ : correlation coefficient; $R^{2}$ : explained variance; $R_{\text {adj }}^{2}$ : explained variance after adjustment for degrees of freedom;

$F: F$ statistic for regression model significance; ST: sign test; ST1: first difference sign test; PMT: product mean test; RE: reduction of error; DW: Durbin-Watson statistic.

capture the anomalous high and low value of the reconstruction. Therefore, the MB was reconstructed back to 1868 using the second model. The reconstruction explained $41.7 \%$ of the recorded MB variance in period 1960-1990. A visual comparison between the recorded $\mathrm{MB}$ and the reconstructed $\mathrm{MB}$ also suggested the reconstruction tracked well the actual $\mathrm{MB}$ values (Fig. $2 \mathrm{~b}$ ). The reconstructed series was characterized by general ablation during the past $140 \mathrm{yr}$. Typical melting periods occurred in 1910s-1920s, 1930s-1960s, 1970s1980s, and the last $20 \mathrm{yr}$ (Fig. 2c).

In order to reveal the variation process of the $\mathrm{MB}$ over the past $140 \mathrm{yr}$, the cumulative mass balance (CMB) was calculated (i.e., the MB was accumulated from the first year). The resultant series showed an obvious ablation trend over the past $140 \mathrm{yr}$, especially since the 1900s. The persistent ablation since the 1900 s was only reversed at three short intervals (i.e., 1920s-1930s, 1960s and the late 1980s) (Fig. 3a). In addition, we found that the reconstructed MB was significantly and negatively correlated with August-September AIR $\left(r_{1781-2008}=-0.342, p<0.0001\right)$ (Fig. 3e), but did not show a significant correlation in other months.

\section{Discussion}

\subsection{Indication of tree-ring growth to glacier mass balance variation}

The significant negative correlation between the MLD and the MB suggested that the mean latewood density of Abies fabri could be a useful indicator of the MB variation at the Hailuogou Glacier, and implied inverse response of the two parameters to the climate condition in the study region determined by different processes. Importantly, among the six available tree-ring parameters (i.e., tree-ring width, earlywood width, latewood width, mean earlywood density, maximum latewood density and mean latewood density), MLD shows the highest correlation with the MB (Fig. 4). The minimum density was not used here because most of the measurement values of this parameter are zero. How did the climate condition drive the two different processes? We examined the relationships between the MLD, the MB and the instrumental climate data (i.e., monthly mean temperature and monthly total precipitation) from the nearest meteorological station (Luding station; Fig. 1a). The results demonstrated that the
MLD correlated positively with May-September temperature $\left(r_{1957-2007}=0.607, p<0.0001\right)$ and negatively with August-September $\left(r_{1957-2007}=-0.317, p<0.05\right)$ precipitation. The correlation coefficient between the MLD and May-September precipitation is $r_{1957-2007}=-0.164$ ( $p=$ 0.265 ). Meanwhile, the MB correlated negatively with MaySeptember temperature $\left(r_{1957-2007}=-0.574, p<0.001\right)$. The correlation coefficient between the MB and MaySeptember precipitation is $r_{1957-2007}=0.180(p=0.33)$. These results indicated that high May-September temperatures (especially August-September temperature) were conducive to photosynthesis, and contributed to latewood cell wall thickening and production of higher latewood density (Duan et al., 2010a), and vice versa. In contrast, high summer temperature could accelerate the melting of glacier. Warming-induced fast retreat of the terminus at the Hailuogou Glacier also has been reported (Li et al., 2010). Importantly, $80 \%$ of the annual precipitation in the study region also occurred in warm season (i.e., May-September) (Fig. 1c). Thus, the significant negative correlation between the MLD and the MB and their inverse response to the same climate condition could be understood as the following. Cold summers with abundant precipitation inhibited tree growth in the region and positively affected the net MB of the glacier. Similarly, but contrary, during hot summers tree-ring growth in the region was usually enhanced, but glaciers showed stronger melting rates. Such a summer climate driving the two different processes was also reported in other studies in high-latitude glacial regions (Lewis and Smith, 2004; Watson and Luckman, 2004; Linderholm et al., 2007).

\subsection{Linkage between the glacier variation and climate variability}

Climate change is the direct cause of glacier variation (Ren et al., 2004). Some studies indicated that glacier shrinkage in some regions in the TP resulted from temperature increase (Ren et al., 2004; Li et al., 2010). However, glacier variation in another region in the TP was related to the Indian summer monsoon precipitation (Thompson et al., 2000; Duan et al., 2004). How did the MS variation at the Hailuogou Glacier in southeastern TP link to long-term climate change? The long-term comparison of the MB variation at the Hailuogou Glacier with regional and Northern Hemisphere temperature change displayed an obvious inverse trend between the 
MS variation and temperature change (Fig. 3a-d). A clear negative phase occurred between the rapid glacier ablation and the increased Northern Hemisphere temperature over the period 1868-2007 (Fig. 3a and b). Most of the accumulation/ablation periods also corresponded to regional low/high temperature intervals (Fig. 3a, c, d). In addition, the $10 \mathrm{yr}$ fast Fourier transform (FFT) smoothing curve of the AugustSeptember AIR (Fig. 3e) also presented a negative phase with the $\mathrm{MB}$ and a positive phase with the regional temperature change. These results suggested that the MB variation at the Hailuogou Glacier was a result of temperature change but not the Indian summer monsoon precipitation. The significant negative correlation between the MB and the AugustSeptember AIR implied that summer heating of the TP has a positive influence on the Indian summer monsoon precipitation, which can be further confirmed by the significant positive correlation between the August-September AIR and the instrumental August-September mean temperature at Luding station $\left(r_{1957-2007}=0.538, p<0.001\right)$. Therefore, we concluded that the MB variation at the Hailuogou Glacier was mainly controlled by temperature variability, while the Indian summer monsoon precipitation did not contribute directly to the glacier accumulation, although it was considered as an important climate system influencing the large-scale precipitation in the TP. The precipitation at the Hailuogou Glacier region might mainly result from the local or other climate systems.

\subsection{Comparison of the reconstructed MB with other glacial records}

In order to further validate our reconstruction and to reveal the spatially heterogeneous response of glacier variation to climate change in the TP, we compared our reconstruction with the frontal retreat velocity in the Hailuogou Glacier (Li et al., 2010) and the ice-core accumulation variations in Guliya $\left(35^{\circ} 17^{\prime} \mathrm{N}, 81^{\circ} 29^{\prime} \mathrm{E}\right)$ and Dasuopu $\left(28^{\circ} 23^{\prime} \mathrm{N}\right.$, $8^{\circ} 43^{\prime}$ E) (Thompson et al., 1997, 2000) (Fig. 5). Our MB reconstruction coincided with the frontal retreat variation of the Hailuogou Glacier generally (Fig. 5b). The strong ablation period of 1930-1960 corresponded to a rapid terminus retreat $\left(31.9 \mathrm{~m} \mathrm{yr}^{-1}\right)$. An increase of the accumulation in the 1960s and the relatively high accumulation in the late 1970s induced slowing down of the retreat velocity in 1966$1983\left(11.8 \mathrm{~m} \mathrm{yr}^{-1}\right)$. Similarly, the strong wastage since the 1980s was also consistent with the increased retreat velocity in 1983-2006 $\left(20.5 \mathrm{myr}^{-1}\right)$. These coherent results can be a validation of our MB reconstruction. The MB variation (Fig. 5b) was also well in agreement with the decadal average net balance fluctuation in the Guliya ice core (Fig. 5c) over the reconstruction period 1868-2007. However, a negative phase occurred between our MB variation and the Dasuopu ice-core accumulation rate (Fig. 5a). Such consistent and inconsistent results can be attributed to the homogenous and heterogeneous response of glacier variation to climate

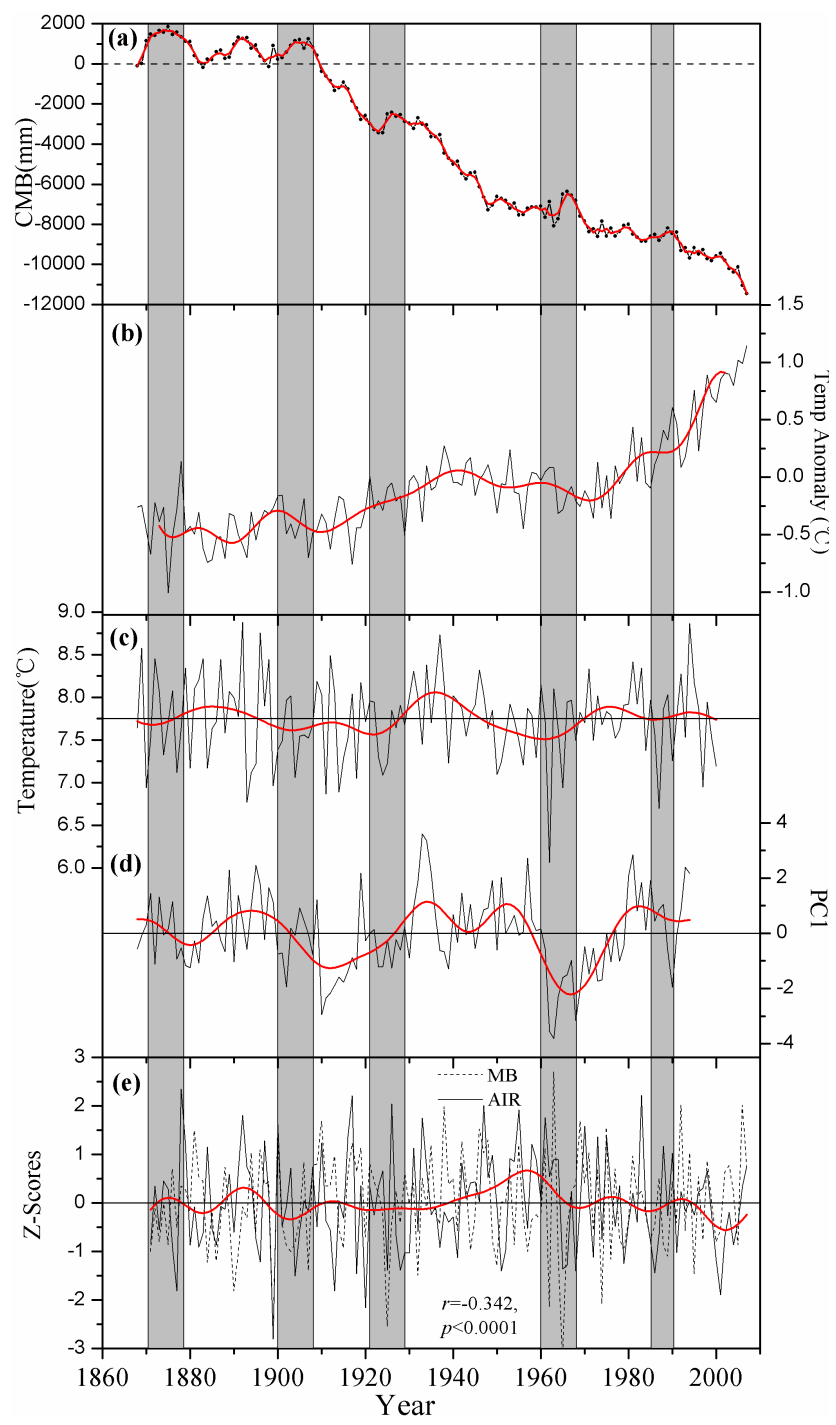

Fig. 3. (a) Cumulative mass balance (CMB) variation (black dotted line) at the Hailuogou Glacier back to 1868 , with a 3-point moving average (red line). (b) Northern Hemisphere annual temperature anomaly (HadCRUT4) over the period 1868-2007 (black line), with a $10 \mathrm{yr}$ FFT (fast Fourier transform) filter (red line). (c) August-September temperature reconstruction for the eastern Tibetan Plateau (letter C in Fig. 1a) during 1868-2000 (Wang et al., 2010), with a $10 \mathrm{yr}$ FFT filter (red line). (d) Reconstructed winter temperature variability (PC1) in the West Sichuan Plateau (letter B in Fig. 1a) (Shao eand Fan, 1999) during the period 1868-1994, with a $10 \mathrm{yr}$ FFT filter (red line). (e) Comparison of the reconstructed MB (was multiplied by -1) with August-September allIndia monsoon precipitation over the period 1871-2007. Red line indicates $10 \mathrm{yr}$ FFT filter of the latter.

change. Thompson et al. (1997) pointed out that the accumulation rate of ice core in Guliya was similar to that observed in polar ice cores, suggesting that the accumulation variation in the Guliya Glacier was controlled mainly by global or large-scale climate change. Differently, the accumulation 

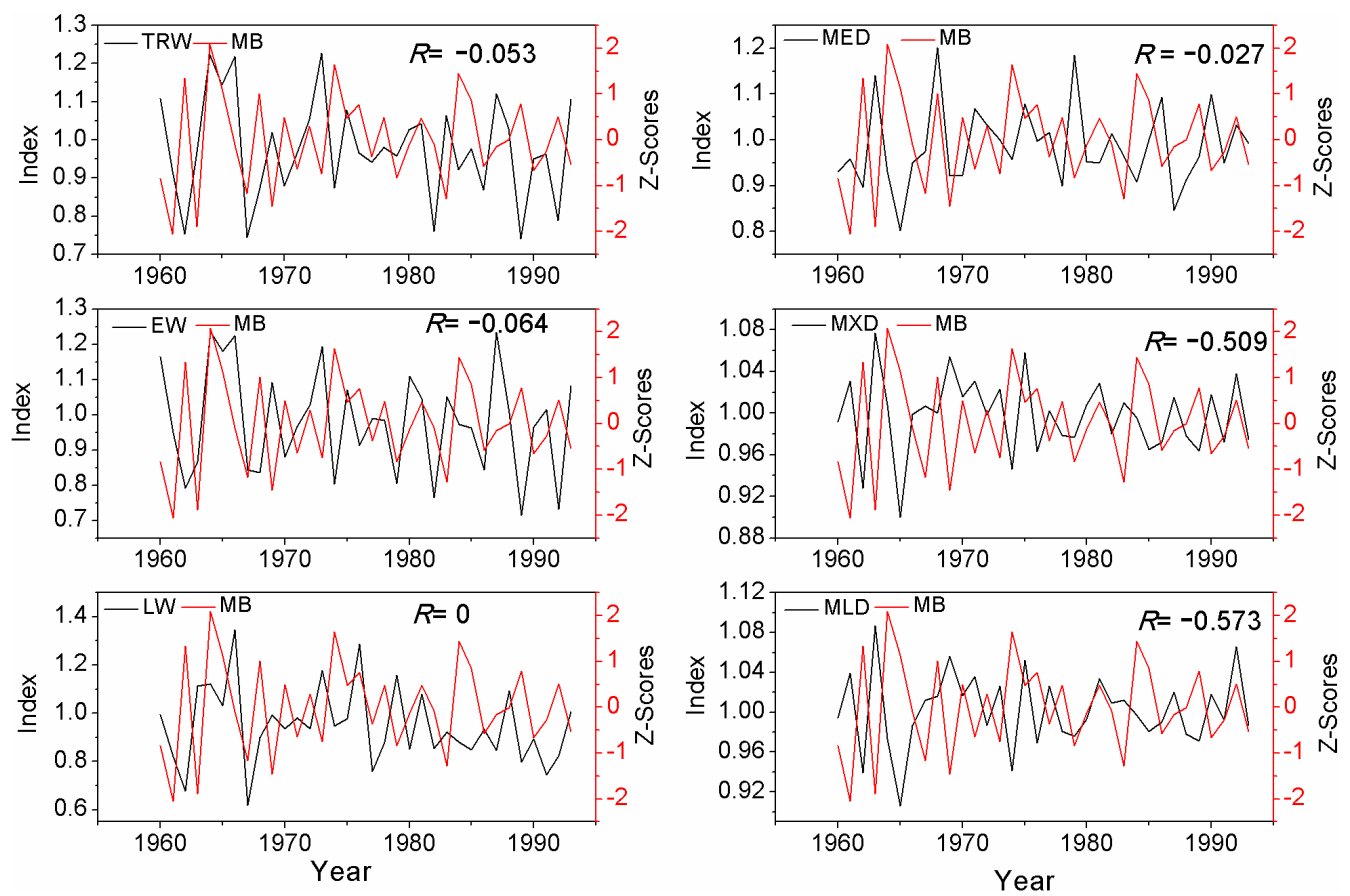

Fig. 4. Comparisons of the residual chronologies of the six tree-ring parameters with the mass balance data over the period $1960-1993$. TRW: tree-ring width; EW: earlywood width; LW: latewood width; MED: mean earlywood density; MXD: maximum latewood density; MLD: mean latewood density.

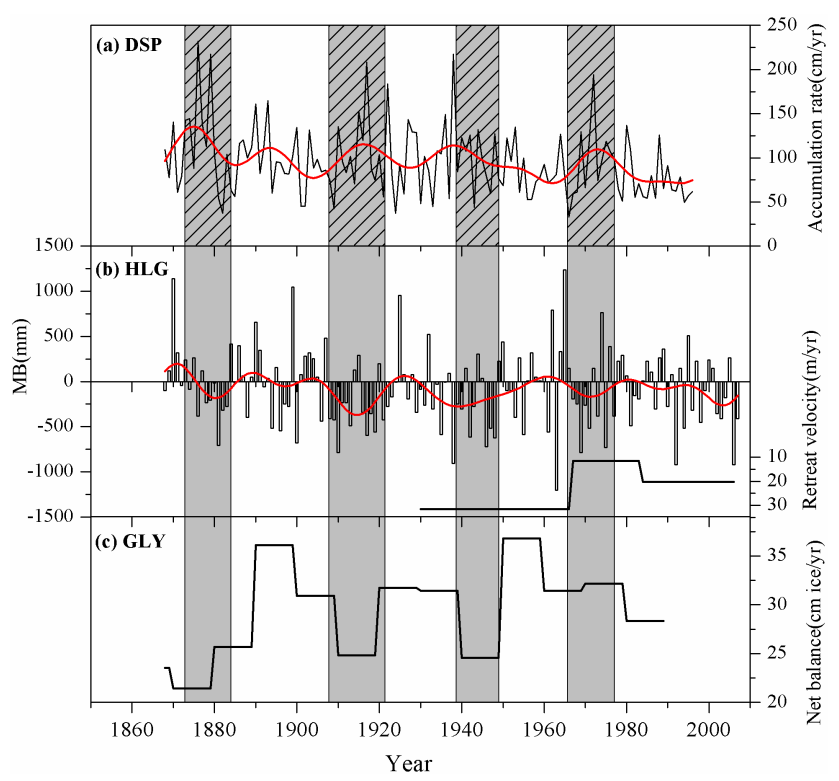

Fig. 5. Comparison of the MB reconstructed in this study (b) with the accumulation rate (annual net balance) recorded in the Dasuopu ice core (Thompson et al., 2000) (a), the mean frontal retreat velocity of the Hailuogou Glacier (Li et al., 2010) (b), and the decadal average of net balance reconstructed by the Guliya ice core (Thompson et al., 1997) (c). Red lines denote 10 yr FFT (fast Fourier transform) filter. rate in the Dasuopu ice core was mainly influenced by Indian summer monsoon precipitation (Thompson et al., 2000; Duan et al., 2004). Our results indicated that the MB variation in the Hailuogou Glacier matched well with regional and Northern Hemisphere temperature anomaly, and was negatively correlated with Indian summer monsoon precipitation (Fig. 3a-e). This could be the main cause of the MB variation and is in line with the ice-core accumulation in Guliya and is contrary in Dasuopu (Fig. 5a-c).

Acknowledgements. This study was funded by the National Natural Science Foundation of China (grants 41101043 and 41271120). We thank the Gongga Alpine Ecosystem Observation Station for giving assistance in field work. We thank Shao X. M. for making her original reconstruction available.

Edited by: J. Guiot

\section{References}

Bolch, T., Kulkarni, A., Kääb, A., Huggel, C., Paul, F., Cogley, J. G., Frey, H., Kargel, J. S., Fujita, K., Scheel, M., Bajracharya, S., and Stoffel, M.: The state and fate of Himalayan glaciers, Science, 336, 310-314, doi:10.1126/science.1215828, 2012.

Bräuning, A.: Tree-ring evidence of "Little Ice Age" glacier advances in southern Tibet, Holocene, 16, 369-380, 2006. 
Bury, J. T., Mark, B. G., McKenzie, J. M., French, A., Baraer, M., Huh, K. I., Luyo, M. A. Z., and Lopez, R. J. G.: Glacier recession and human vulnerability in the Yanamarey watershed of the Cordillera Blanca, Peru, Climatic Change, 105, 179-206, doi:10.1007/s10584-010-9870-1, 2011.

Cook, E. R. and Kairiukstis, L. A. (Eds.): Methods of Dendrochronology: Applications in the Environmental Sciences, Kluwer Academic Publishers, Dordrecht, 394 pp., 1990.

Duan, J. P., Wang, L., Li, L., and Chen, K. L.: Temperature variability since AD 1837 inferred from tree-ring maximum density of Abies fabri on Gongga Mountain, China, Chinese Sci. Bull., 55, 3015-3022, doi:10.1007/s11434-010-3182-8, 2010a.

Duan, J. P., Wang, L., Xu, Y., Sun, Y., and Chen, J.: Response of tree-ring width to climate change at different elevations on the east slope of Gongga Mountains, Geogr. Res., 29, 1940-1949, 2010b (in Chinese).

Duan, K. Q., Yao, T. D., and Thompson, L. G.: Low-frequency of southern Asian monsoon variability using a 295-year record from the Dasuopu ice core in the central Himalayas, Geophys. Res. Lett., 31, L16209, doi:10.1029/2004g1020015, 2004.

Fritts, H. C. (Ed.): Tree Rings and Climate, Academic Press, London, 567 pp., 1976.

Fujita, K. and Nuimura, T.: Spatially heterogeneous wastage of Himalayan glaciers, P. Natl. Acad. Sci. USA, 108, 14011-14014, doi:10.1073/pnas.1106242108, 2011.

Jacob, T., Wahr, J., Pfeffer, W. T., and Swenson, S.: Recent contributions of glaciers and ice caps to sea level rise, Nature, 482, 514-518, doi:10.1038/Nature10847, 2012.

Jansen, E., Overpeck, J., Briffa, K., Duplessy, J.-C., Joos, F., Masson-Delmotte, V., Olago, D., Otto-Bliesner, B., Peltier, W., Rahmstorf, S., Ramesh, R., Raynaud, D., Rind, D., Solomina, O., Villalba, R., and Zhang, D.: Palaeoclimate, Chapter 6, in: Climate Change 2007: The Physical Science Basis, Contribution of Working Group I to the Fourth Assessment Report of the Intergovernmental Panel on Climate Change, edited by: Solomon, S., Qin, D., Manning, M., Chen, Z., Marquis, M., Averyt, K., Tignor, M., and Miller, H., Cambridge University Press, Cambridge, United Kingdom and New York, NY, USA, 2007.

Jones, P. D., Lister, D. H., Osborn, T. J., Harpham, C., Salmon, M., and Morice, C. P.: Hemispheric and large-scale land-surface air temperature variations: An extensive revision and an update to 2010, J. Geophys. Res., 117, D05127, doi:10.1029/2011jd017139, 2012.

Kääb, A., Berthier, E., Nuth, C., Gardelle, J., and Arnaud, Y.: Contrasting patterns of early twenty-first-century glacier mass change in the Himalayas, Nature, 488, 495-498, doi:10.1038/nature11324, 2012.

Lenz, O., Schaer, E., and Schweingruber, F. H.: Methodological problems relative to the measurement of the density and width of growth rings by X-ray densitograms of wood, Holzforschung, 30, 114-123, 1976.

Lewis, D. and Smith, D.: Dendrochronological mass balance reconstruction, Strathcona Provincial Park, Vancouver Island, British Columbia, Canada, Arct. Antarct. Alp. Res., 36, 598606, doi:10.1657/1523-0430(2004)036[0598:Dmbrsp]2.0.Co;2, 2004.

Li, Z. X., He, Y. Q., Pu, T., Jia, W. X., He, X. Z., Pang, H. X., Zhang, N. N., Liu, Q., Wang, S. J., Zhu, G. F., Wang, S. X., Chang, L., Du, J. K., and Xin, H. J.: Changes of climate, glaciers and runoff in China's monsoonal temperate glacier region during the last several decades, Quatern. Int., 218, 13-28, doi:10.1016/j.quaint.2009.05.010, 2010.

Linderholm, H. W., Jansson, P., and Chen, D. L.: A high-resolution reconstruction of Storglaciaren mass balance back to 1780/81 using tree-ring data and circulation indices, Quaternary Res., 67, 12-20, doi:10.1016/j.yqres.2006.08.005, 2007.

Liu, J. P., Curry, J. A., Wang, H. J., Song, M. R., and Horton, R. M.: Impact of declining Arctic sea ice on winter snowfall, P. Natl. Acad. Sci. USA, 109, 4074-4079, doi:10.1073/pnas.1114910109, 2012.

Michaelsen, J.: Cross-Validation in Statistical Climate Forecast Models, J. Clim. Appl. Meteorol., 26, 1589-1600, doi:10.1175/1520-0450(1987)026<1589:Cviscf>2.0.Co;2, 1987.

Ren, J. W., Qin, D. H., Kang, S. C., Hou, S. G., Pu, J. C., and Jing, Z. F.: Glacier variations and climate warming and drying in the central Himalayas, Chinese Sci. Bull., 49, 65-69, doi:10.1360/03wd0148, 2004.

Scherler, D., Bookhagen, B., and Strecker, M. R.: Spatially variable response of Himalayan glaciers to climate change affected by debris cover, Nat. Geosci., 4, 156-159, doi:10.1038/Ngeo1068, 2011.

Schweingruber, F. H., Bartholin, T., Schar, E., and Briffa, K. R.: Radiodensitometric-Dendroclimatological Conifer Chronologies from Lapland (Scandinavia) and the Alps (Switzerland), Boreas, 17, 559-566, 1988.

Shao, X. M. and Fan, J. M.: Past climate on west Sichuan Plateau as reconstructed from ring-widths of dragon spruce, Quaternary Sciences, 19, 81-89, 1999 (in Chinese).

Shi, Y. F. (Ed.): Glaciers and their environments in China-the present, past and future, Science Press, Beijing, 2000 (in Chinese).

Shi, Y. F. (Ed.): A concise China glacier inventory, Shanghai Science Popularization Press, Shanghai, 2005 (in Chinese).

Thompson, L. G., Yao, T., Davis, M. E., Henderson, K. A., MosleyThompson, E., Lin, P.-N., Beer, J., Synal, H.-A., ColeDai, J., and Bolzan, J. F.: Tropical climate instability: The last glacial cycle from a Qinghai-Tibetan ice core, Science, 276, 1821-1825, doi:10.1126/science.276.5320.1821, 1997.

Thompson, L. G., Yao, T., Mosley-Thompson, E., Davis, M. E., Henderson, K. A., and Lin, P.-N.: A high-resolution millennial record of the South Asian Monsoon from Himalayan ice cores, Science, 289, 1916-1919, doi:10.1126/science.289.5486.1916, 2000.

Wang, L., Duan, J. P., Chen, J., Huang, L., and Shao, X. M.: Temperature reconstruction from tree-ring maximum density of Balfour spruce in eastern Tibet, China, Int. J. Climatol., 30, 972-979, doi:10.1002/Joc.2000, 2010.

Watson, E. and Luckman, B. H.: Tree-ring-based mass-balance estimates for the past 300 years at Peyto Glacier, Alberta, Canada, Quaternary Res., 62, 9-18, doi:10.1016/j.yqres.2004.04.007, 2004.

Wigley, T. M. L., Briffa, K. R., and Jones, P. D.: On the average value of correlated time-series, with applications in dendroclimatology and hydrometeorology, J. Clim. Appl. Meteorol., 23, 201-213, doi:10.1175/15200450(1984)023<0201:Otavoc>2.0.Co;2, 1984.

Xu, P., Zhu, H. F., Shao, X. M., and Yin, Z. Y.: Tree ring-dated fluctuation history of Midui glacier since the little ice age in the 
southeastern Tibetan plateau, Science China Earth Sciences, 55, 521-529, 2012.

Yao, T. D., Pu, J. C., Lu, A. X., Wang, Y. Q., and Yu, W. S.: Recent glacial retreat and its impact on hydrological processes on the tibetan plateau, China, and sorrounding regions, Arct. Antarct. Alp. Res., 39, 642-650, doi:10.1657/1523-0430(07510)[Yao]2.0.Co;2, 2007.

Yao, T. D., Thompson, L., Yang, W., Yu, W. S., Gao, Y., Guo, X. J., Yang, X. X., Duan, K. Q., Zhao, H. B., Xu, B. Q., Pu, J. C., Lu, A. X., Xiang, Y., Kattel, D. B., and Joswiak, D.: Different glacier status with atmospheric circulations in Tibetan Plateau and surroundings, Nature Climate Change, 2, 663-667, doi:10.1038/Nclimate1580, 2012.
Yarnal, B.: Relationships between synoptic-scale atmospheric circulation and glacier mass balance in southwestern Canada during the International Hydrological Decade, 1965-74, J. Glaciol., 30, 188-198, 1984.

Zhang, Y., Fujita, K., Liu, S. Y., Liu, Q. A., and Wang, X.: Multidecadal ice-velocity and elevation changes of a monsoonal maritime glacier: Hailuogou Glacier, China, J. Glaciol., 56, 65-74, 2010 . 